\title{
Effects of Routine Checkups and Chronic Conditions on Middle-Aged Patients with Diabetes
}

\author{
America E. McGuffee $\mathbb{D}^{\mathrm{D}}$, Kailyn Chillag, Amber Johnson, Regan Richardson, \\ Hallie Williams, and Jessica Hartos
}

Department of Physician Assistant Studies, University of North Texas Health Science Center, Fort Worth, TX, USA

Correspondence should be addressed to America E. McGuffee; america.mcguffee@unthsc.edu

Received 18 June 2019; Accepted 28 August 2019; Published 26 February 2020

Academic Editor: Gerardo E. Guillén Nieto

Copyright (C) 2020 America E. McGuffee et al. This is an open access article distributed under the Creative Commons Attribution License, which permits unrestricted use, distribution, and reproduction in any medium, provided the original work is properly cited.

\begin{abstract}
Purpose. Middle-aged males and females with diabetes are more likely to have poor physical (PH) and mental health (MH); however, there is limited research determining the relationship between $\mathrm{MH}$ and $\mathrm{PH}$ and routine check-up in diabetic middle-aged adults, especially by gender. The purpose of this study was to determine whether $\mathrm{PH}$ and $\mathrm{MH}$ status differ by routine check-up in middleaged (age 45-64) adults with diabetes in the general population. Methods. This cross-sectional analysis used data from the 2017 BRFSS conducted by the CDC for adults aged 45-64 who reported having diabetes in Florida $(N=1183)$, Kentucky $(N=617)$, Maryland $(N=731)$, New York $(N=593)$, and Ohio $(N=754)$. Multiple logistic regression by state and gender was used to determine the relationship between $\mathrm{MH}$ and $\mathrm{PH}$ status and routine check-up while controlling for health-related, socioeconomic, and demographic factors. Results. Across states, up to one-half reported good PH (32-50\%), over one-half reported good MH (46-67\%), and most reported having a routine check-up (87-93\%). Adjusted analysis indicated that $\mathrm{MH}$ and $\mathrm{PH}$ were not significantly related to routine check-up, but both were inversely related to having diabetes plus two other health conditions. Conclusions. Overall, routine check-up was not related to good $\mathrm{PH}$ and $\mathrm{MH}$ in this target population; however, a number of health conditions were inversely related to good $\mathrm{PH}$ and $\mathrm{MH}$ status. In a primary care setting for this target population, there may be a low to moderate prevalence of good $\mathrm{PH}$ and $\mathrm{MH}$ and a high prevalence of having a routine check-up and having multiple health conditions. It is recommended to automatically screen this target population for $\mathrm{PH}, \mathrm{MH}$, other chronic conditions, and physical activity and treat concurrently.
\end{abstract}

\section{Introduction}

Through utilization of preventative health examinations and routine checkups, the most common chronic physical and mental health conditions can be prevented, delayed, or treated more effectively $[6,11]$. Visits of this type are linked with improved physical and mental health outcomes $[4,5,14]$ as well as to improvements in health-related quality of life (HRQoL) and control over diseases [10]. However, research indicates that both engagement in preventative health checks and overall perception of one's health differ based on demographic factors, socioeconomic status, health insurance coverage, lifestyle factors, and disease burden $[4,5,9,10,12-14]$.

Diabetes is a significant component of the disease burden in the US as it affects up to 30 million adults, and of those, up to 7 million may be undiagnosed (not aware of or did not report having DM) [2]. Because this condition is chronic and progressive, it can lead to other physical and mental health complications over time $[10-12,14]$. In addition, those with diabetes report lower HRQoL ratings than do individuals without chronic illnesses [10]. Thus, annual or more frequent checkups would be necessary for persons with diabetes as research indicates that preventative care decreases both the prevalence and progression of this condition [6].

However, research for associations between routine checkups and physical or mental health tends to focus on older adults/Medicare users [4-6], with no studies assessing these relations for differences by gender $[9,12-14]$ or by diabetes status $[4,7,8]$. Therefore, the purpose of this study is to assess whether physical and mental health differ by receiving a routine checkup in middle-aged males and females with diabetes. 
TABLE 1

(a): Participant characteristics by state: diabetic males.

\begin{tabular}{|c|c|c|c|c|c|c|c|c|c|c|}
\hline \multirow{2}{*}{ Variable } & \multicolumn{2}{|c|}{ Florida $(N=516)$} & \multicolumn{2}{|c|}{ Kentucky $(N=236)$} & \multicolumn{2}{|c|}{ Maryland $(N=311)$} & \multicolumn{2}{|c|}{ New York $(N=300)$} & \multicolumn{2}{|c|}{ Ohio $(N=323)$} \\
\hline & $N$ & $\%$ & $N$ & $\%$ & $N$ & $\%$ & $N$ & $\%$ & $N$ & $\%$ \\
\hline Good mental health & 516 & 100 & 236 & 100 & 311 & 100 & 300 & 100 & 323 & 100 \\
\hline Yes & 333 & 65 & 131 & 56 & 207 & 67 & 199 & 66 & 209 & 65 \\
\hline No & 183 & 35 & 105 & 44 & 104 & 33 & 101 & 34 & 114 & 35 \\
\hline Good physical health & 516 & 100 & 236 & 100 & 311 & 100 & 300 & 100 & 323 & 100 \\
\hline Yes & 232 & 45 & 87 & 37 & 154 & 50 & 141 & 47 & 142 & 44 \\
\hline No & 284 & 55 & 149 & 63 & 157 & 50 & 159 & 53 & 181 & 56 \\
\hline Routine checkup & 516 & 100 & 236 & 100 & 311 & 100 & 300 & 100 & 323 & 100 \\
\hline Yes & 451 & 87 & 213 & 90 & 280 & 90 & 268 & 89 & 292 & 90 \\
\hline No & 65 & 13 & 23 & 10 & 31 & 10 & 32 & 11 & 31 & 10 \\
\hline Health conditions & 475 & 92 & 218 & 92 & 296 & 95 & 286 & 95 & 302 & 93 \\
\hline $\begin{array}{l}0 \text { or } 1 \text { other health } \\
\text { condition }\end{array}$ & 101 & 21 & 34 & 16 & 67 & 23 & 84 & 29 & 55 & 18 \\
\hline $\begin{array}{l}2 \text { other health } \\
\text { conditions }\end{array}$ & 374 & 79 & 184 & 84 & 229 & 77 & 202 & 71 & 247 & 82 \\
\hline Physical activity & 461 & 89 & 214 & 91 & 270 & 87 & 248 & 83 & 300 & 93 \\
\hline Inactive & 195 & 42 & 101 & 47 & 90 & 33 & 95 & 38 & 126 & 42 \\
\hline Insufficiently active & 90 & 20 & 48 & 22 & 60 & 22 & 52 & 21 & 62 & 21 \\
\hline Active/Highly active & 176 & 38 & 65 & 30 & 120 & 44 & 101 & 41 & 112 & 37 \\
\hline Weight status & 487 & 94 & 230 & 97 & 295 & 95 & 287 & 96 & 315 & 98 \\
\hline Underweight or normal & 53 & 11 & 27 & 12 & 34 & 12 & 32 & 11 & 34 & 11 \\
\hline Overweight & 149 & 31 & 64 & 28 & 83 & 28 & 99 & 34 & 83 & 26 \\
\hline Obese & 285 & 59 & 139 & 60 & 178 & 60 & 156 & 54 & 198 & 63 \\
\hline Tobacco use & 495 & 96 & 229 & 97 & 296 & 95 & 277 & 92 & 315 & 98 \\
\hline Never & 221 & 45 & 78 & 34 & 149 & 50 & 151 & 55 & 154 & 49 \\
\hline Former & 182 & 37 & 82 & 36 & 90 & 30 & 85 & 31 & 113 & 36 \\
\hline Current & 92 & 19 & 69 & 30 & 57 & 19 & 41 & 15 & 48 & 15 \\
\hline Alcohol use & 495 & 96 & 228 & 97 & 298 & 96 & 293 & 98 & 313 & 97 \\
\hline None & 299 & 60 & 157 & 69 & 146 & 49 & 138 & 47 & 182 & 58 \\
\hline Light & 57 & 12 & 27 & 12 & 42 & 14 & 46 & 16 & 42 & 13 \\
\hline Moderate or excessive & 139 & 28 & 44 & 19 & 110 & 37 & 109 & 37 & 89 & 28 \\
\hline Age & 516 & 100 & 236 & 100 & 311 & 100 & 300 & 100 & 323 & 100 \\
\hline $45-54$ & 176 & 34 & 76 & 32 & 107 & 34 & 103 & 34 & 83 & 26 \\
\hline 55-64 & 340 & 66 & 160 & 68 & 204 & 66 & 197 & 66 & 240 & 74 \\
\hline Ethnicity/Race & 506 & 98 & 234 & 99 & 304 & 98 & 288 & 96 & 313 & 97 \\
\hline White & 328 & 65 & 186 & 79 & 191 & 63 & 162 & 56 & 272 & 87 \\
\hline Other & 178 & 35 & 48 & 21 & 113 & 37 & 126 & 44 & 41 & 13 \\
\hline Marital status & 511 & 99 & 235 & 99 & 310 & 100 & 299 & 100 & 321 & 99 \\
\hline Married & 292 & 57 & 130 & 55 & 187 & 60 & 145 & 48 & 190 & 59 \\
\hline Not married & 219 & 43 & 105 & 45 & 123 & 40 & 154 & 52 & 131 & 41 \\
\hline Education level & 515 & 100 & 233 & 99 & 310 & 100 & 297 & 99 & 321 & 99 \\
\hline Graduated college & 126 & 25 & 56 & 24 & 209 & 33 & 93 & 31 & 75 & 23 \\
\hline $\begin{array}{l}\text { Did not graduate } \\
\text { college }\end{array}$ & 389 & 76 & 177 & 76 & 101 & 67 & 204 & 69 & 246 & 77 \\
\hline Income level & 464 & 90 & 182 & 77 & 272 & 87 & 272 & 91 & 287 & 89 \\
\hline$\$ 50,000$ or more & 142 & 31 & 65 & 36 & 164 & 60 & 103 & 38 & 123 & 43 \\
\hline Less than $\$ 50,000$ & 322 & 69 & 117 & 64 & 108 & 40 & 169 & 62 & 164 & 57 \\
\hline Employment status & 512 & 99 & 235 & 99 & 309 & 99 & 291 & 97 & 322 & 99 \\
\hline Employed & 217 & 42 & 94 & 40 & 181 & 59 & 147 & 51 & 154 & 48 \\
\hline Other & 295 & 58 & 141 & 60 & 128 & 41 & 144 & 49 & 158 & 52 \\
\hline
\end{tabular}


TABLE 1: Continued.

(b): Participant characteristics by state: females with diabetes.

\begin{tabular}{|c|c|c|c|c|c|c|c|c|c|c|}
\hline \multirow{2}{*}{ Variable } & \multicolumn{2}{|c|}{ Florida $(N=667)$} & \multicolumn{2}{|c|}{ Kentucky $(N=381)$} & \multicolumn{2}{|c|}{ Maryland $(N=420)$} & \multicolumn{2}{|c|}{ New York $(N=293)$} & \multicolumn{2}{|c|}{ Ohio $(N=431)$} \\
\hline & $N$ & $\%$ & $N$ & $\%$ & $N$ & $\%$ & $N$ & $\%$ & $N$ & $\%$ \\
\hline Good mental health & 667 & 100 & 381 & 100 & 420 & 100 & 293 & 100 & 431 & 100 \\
\hline Yes & 331 & 50 & 197 & 52 & 232 & 55 & 134 & 46 & 205 & 48 \\
\hline No & 336 & 50 & 184 & 48 & 188 & 45 & 159 & 54 & 226 & 52 \\
\hline Good physical health & 667 & 100 & 381 & 100 & 420 & 100 & 293 & 100 & 431 & 100 \\
\hline Yes & 258 & 39 & 123 & 32 & 193 & 46 & 96 & 33 & 162 & 38 \\
\hline No & 409 & 61 & 258 & 68 & 227 & 54 & 197 & 67 & 269 & 62 \\
\hline Routine checkup & 667 & 100 & 381 & 100 & 420 & 100 & 293 & 100 & 431 & 100 \\
\hline Yes & 580 & 87 & 353 & 93 & 372 & 89 & 267 & 91 & 391 & 91 \\
\hline No & 87 & 13 & 28 & 7 & 48 & 11 & 26 & 9 & 40 & 9 \\
\hline Health conditions & 605 & 91 & 355 & 90 & 398 & 95 & 274 & 94 & 395 & 92 \\
\hline $\begin{array}{l}0 \text { or } 1 \text { other health } \\
\text { condition }\end{array}$ & 115 & 19 & 51 & 14 & 78 & 20 & 52 & 19 & 62 & 16 \\
\hline $\begin{array}{l}2 \text { other health } \\
\text { conditions }\end{array}$ & 490 & 81 & 304 & 86 & 320 & 80 & 222 & 81 & 333 & 84 \\
\hline Physical activity & 610 & 91 & 344 & 90 & 365 & 87 & 250 & 85 & 401 & 93 \\
\hline Inactive & 294 & 48 & 189 & 55 & 150 & 41 & 107 & 43 & 198 & 49 \\
\hline Insufficiently active & 116 & 19 & 872 & 21 & 74 & 20 & 5 & 22 & 83 & 21 \\
\hline Active/Highly active & 200 & 33 & 83 & 24 & 141 & 39 & 88 & 35 & 120 & 30 \\
\hline Weight status & 589 & 88 & 335 & 88 & 378 & 90 & 270 & 92 & 388 & 90 \\
\hline Underweight or normal & 91 & 15 & 44 & 13 & 4343 & 11 & 41 & 15 & 31 & 8 \\
\hline Overweight & 147 & 25 & 92 & 27 & 90 & 24 & 73 & 27 & 94 & 24 \\
\hline Obese & 351 & 60 & 199 & 59 & 245 & 65 & 156 & 58 & 263 & 68 \\
\hline Tobacco use & 643 & 96 & 375 & 98 & 398 & 95 & 275 & 94 & 422 & 98 \\
\hline Never & 325 & 51 & 180 & 48 & 232 & 58 & 143 & 52 & 211 & 50 \\
\hline Former & 166 & 26 & 108 & 29 & 105 & 26 & 78 & 28 & 111 & 26 \\
\hline Current & 152 & $24 \$$ & 87 & 23 & 61 & 15 & 54 & 20 & 100 & 24 \\
\hline Alcohol use & 656 & 98 & 379 & 99 & 410 & 98 & 284 & 97 & 420 & 97 \\
\hline None & 473 & 72 & 303 & 80 & 227 & 55 & 143 & 60 & 307 & 73 \\
\hline Light & 68 & 10 & 35 & $9^{\wedge}$ & 85 & 21 & 78 & 14 & 64 & 15 \\
\hline Moderate or excessive & 115 & 18 & 41 & 11 & 98 & 24 & 54 & 26 & 49 & 12 \\
\hline Age & 667 & 100 & 381 & 100 & 420 & 100 & 293 & 100 & 431 & 100 \\
\hline $45-54$ & 234 & 35 & 140 & 37 & 140 & 33 & 120 & 41 & 134 & 31 \\
\hline $55-64$ & 433 & 65 & 241 & 63 & 280 & 67 & 173 & 59 & 297 & 69 \\
\hline Ethnicity/Race & 651 & 98 & 377 & 99 & 416 & 99 & 279 & 95 & 427 & 99 \\
\hline White & 426 & 65 & 309 & 82 & 230 & 55 & 162 & 58 & 348 & 82 \\
\hline Other & 225 & 35 & 68 & 18 & 186 & 44 & 117 & 42 & 79 & 19 \\
\hline Marital status & 666 & 100 & 379 & 99 & 417 & 99 & 288 & 98 & 429 & 100 \\
\hline Married & 300 & 45 & 196 & 52 & 200 & 48 & 118 & 41 & 205 & 48 \\
\hline Not married & 366 & 55 & 183 & 48 & 217 & 52 & 170 & 59 & 224 & 52 \\
\hline Education level & 667 & 100 & 380 & 100 & 420 & 100 & 291 & 99 & 429 & 100 \\
\hline Graduated college & 137 & 21 & 83 & 22 & 142 & 34 & 92 & 32 & 95 & 22 \\
\hline Did not graduate college & 530 & 79 & 297 & 78 & 278 & 66 & 199 & 68 & 334 & 78 \\
\hline Income level & 544 & 82 & 268 & 70 & 357 & 85 & 256 & 86 & 372 & 86 \\
\hline$\$ 50,000$ or more & 130 & 24 & 94 & 35 & 179 & 50 & 86 & 34 & 117 & 31 \\
\hline Less than $\$ 50,000$ & 414 & 76 & 174 & 65 & 178 & 50 & 170 & 66 & 255 & 69 \\
\hline Employment status & 662 & 99 & 379 & 99 & 418 & 100 & 287 & 98 & 430 & 100 \\
\hline Employed & 235 & 36 & 133 & 35 & 213 & 51 & 128 & 45 & 164 & 38 \\
\hline Other & 427 & 65 & 246 & 65 & 205 & 49 & 159 & 55 & 266 & 62 \\
\hline
\end{tabular}




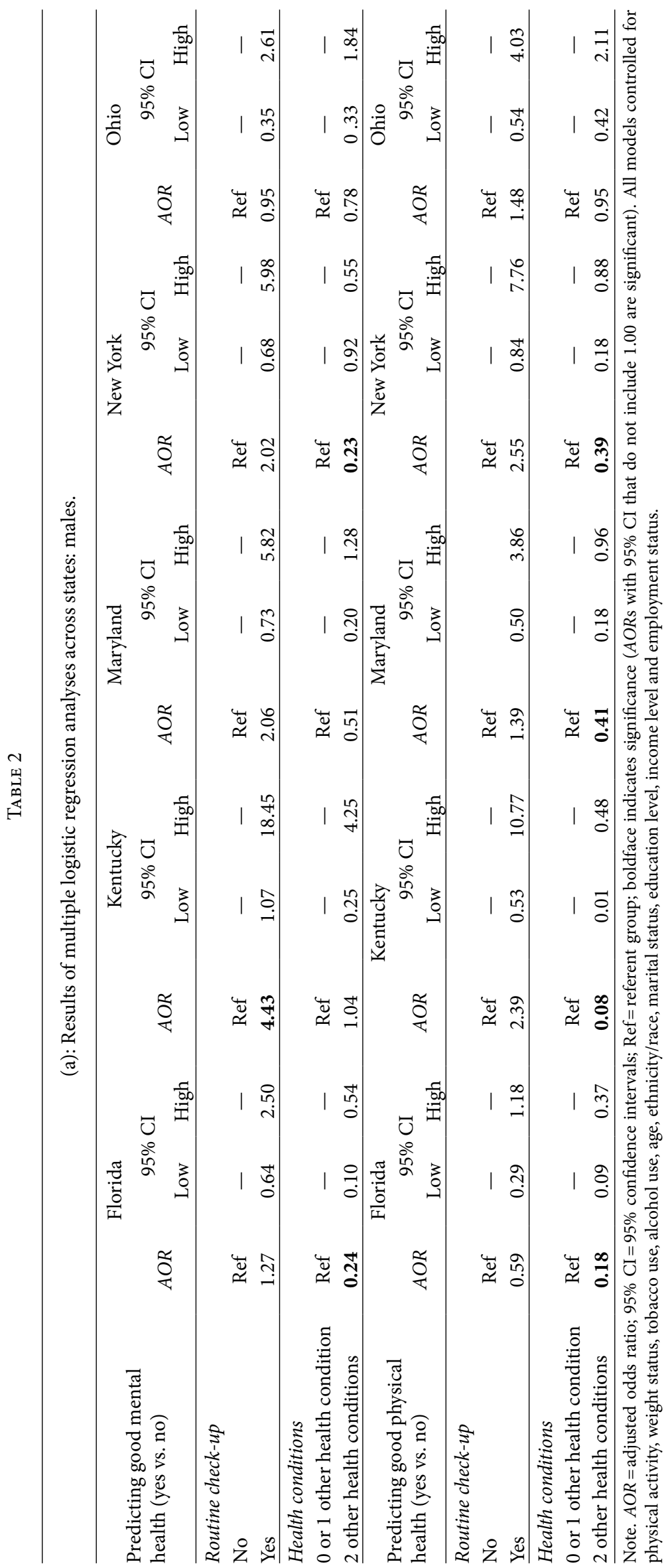




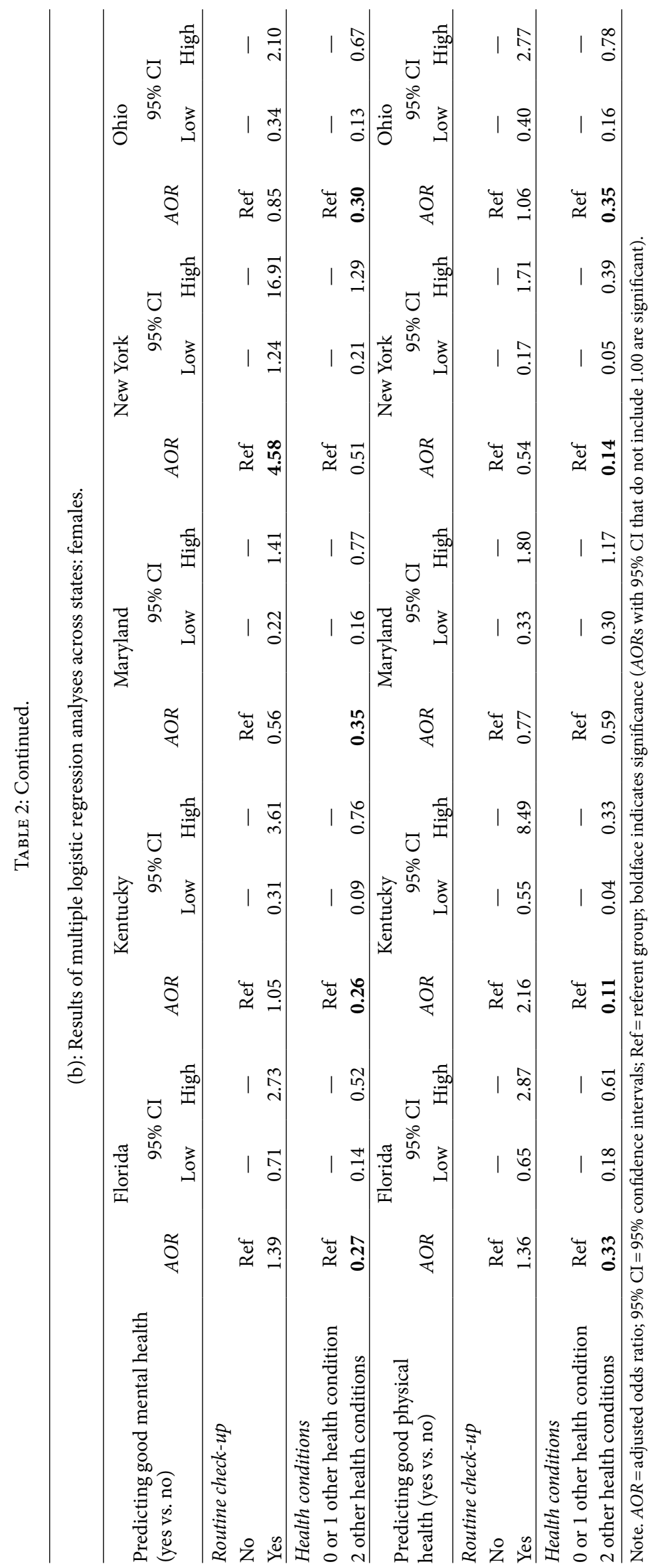




\section{Methods}

2.1. Design. This study is a cross-sectional analysis that used data from the 2017 Behavioral Risk Factor Surveillance System (BRFSS) conducted by the Centers for Disease Control and Prevention (CDC) [3]. BRFSS is an annual telephone survey system that uses random digit dialing techniques for both landlines and cell phones across all 50 states in the US and the District of Columbia. This survey gathers data about US adult residents' health-related behaviors, chronic health conditions, and use of preventative services. The CDC compiles all BRFSS data and makes deidentified data available for secondary analysis by researchers. This study was given exempt status by the Institutional Review Board of The University of North Texas Health Science Center.

2.2. Sample. The samples in the study include males and females with diabetes between the ages of 45 and 64 in Florida $(N=1183)$, $\operatorname{Kentucky}(N=617)$, Maryland $(N=731)$, New York $(N=593)$, and Ohio $(N=754)$ that had data for mental health, physical health, and routine checkup. These states were chosen because they had a large diabetic population and higher rates of fair/poor health status when compared to the other states [1].

2.3. Data. The original BRFSS variables for mental and physical health were determined by asking participants to self-report the number of "poor health days" in the past 30 days separately for mental health and physical health. Because these responses were highly skewed toward 0 days in each state and because we wanted to predict "good" health, we reversed and dichotomized these values to represent "yes" (30 days of good health in the past 30 days) or "no" (fewer than 30 days of good health in the past 30 days) separately for "good mental health" and "good physical health." The factor of interest, routine check-up, was measured as yes/no to having a checkup in the past year.

All models controlled for physical activity, weight status, tobacco use, alcohol use, education level, income level, employment status, age, ethnicity/race, and marital status. Health conditions were measured as the number of "yes" responses to whether participants had any of the following: heart attack, coronary heart disease, stroke, asthma, skin cancer, cancer, COPD, arthritis, depression, kidney disease, and diabetes. The resulting numbers were then categorized as "diabetes only," "diabetes plus one other chronic condition," and "diabetes plus two other chronic conditions." Alcohol use was measured in BRFSS as number of drinks per day and we categorized the numbers as "none," "light" $(<1)$, and "moderate or excessive" (1-4+ females, 1-5+ males). All variables and their categories are shown in Table 1(a).

2.4. Analysis. Frequency distributions by state were used to describe the samples. Multiple logistic regression was conducted by state and gender to determine the relationship between mental and physical health status and routine checkup while controlling for health-related, socioeconomic, and demographic factors. The state and gender data were analyzed separately to determine the relationship between the variables across multiple similar samples within our population of interest. As such, similar results in three out of five states were considered reliable evidence for relations. Any observations with missing data for any variable were excluded from the adjusted analysis and all analyses were conducted in STATA Version 15.1 (Copyright 1985-2017 StataCorp LLC).

\section{Results}

3.1. Participant Characteristics: Males with Diabetes. Table 1(a) lists participant characteristics for middle-aged males with diabetes. The majority of participants had attended a routine medical checkup within the past year (87-90\%) and reported good mental health (56-67\%), but less than half reported good physical health (37-50\%). Regarding health conditions, most participants had diabetes plus two or more chronic illnesses (71-84\%) and were obese (54-63\%), yet less than half reported being inactive (33-47\%). Regarding health behaviors, one-third to one-half of participants did not use tobacco products (34$55 \%)$ or alcohol (47-69\%). For demographics, the majority of participants were married (48-60\%) and reported their race as white (56-87\%). As for socioeconomic status, the majority of respondents had not graduated from college or technical school (67-77\%), approximately half were employed (40-59\%), and up to two-thirds earned an income of $\$ 50,000$ or more (40-69\%).

\subsection{Participant Characteristics: Females with Diabetes.} Table 1(b) lists participant characteristics for middle-aged females with diabetes. Most participants reported having a routine checkup within the past year (87-93\%). About half of the participants reported good mental health (46-55\%) and less than half reported good physical health (32-46\%). Regarding health conditions, most participants had diabetes plus two or more chronic conditions (80-86\%) and were obese (58-68\%), and about one-third to one-half reported being inactive (41$55 \%)$. Regarding health behaviors, the majority of participants reported no tobacco (48-58\%) or alcohol use (55-80\%). For demographics, a range of participants reported their race as white (55-82\%) and around one half were married (41-52\%). As for socioeconomic status, the majority of respondents had not graduated from college or technical school (66-79\%) and earned an income of less than $\$ 50,000$ (50-76\%), while onethird to one-half of participants were employed (35-51\%).

3.3. Mental Health: Males. As shown in Table 2(a), the results of multiple logistic regression analysis for middle-aged males with diabetes indicated that after controlling for all other variables in the model, good mental health was significantly related to having had routine checkups in only 1 out of 5 states, which was not considered a reliable finding across states as was defined in the methods section.

3.4. Physical Health: Males. Also shown in Table 2(a), the results of multiple logistic regression analysis for middleaged males with diabetes indicated that after controlling for all other variables in the model, good physical health was not significantly related to routine checkups across in any state. However, those who reported having diabetes plus two or 
more other chronic conditions were about 2.5-12.5 times less likely to report good physical health compared to those who reported diabetes only across states.

3.5. Mental Health: Females. As shown in Table 2(b), the results of multiple logistic regression analysis for middle-aged females with diabetes indicated that after controlling for all other variables in the model, good mental health was significantly related to having routine checkups in only 1 out of the 5 states, which was not considered a reliable finding across similar samples. However, compared to those with only diabetes, those who reported having diabetes plus two or more other chronic conditions were approximately three to four times less likely to report good mental health compared to those who reported having diabetes only in a majority of the states.

3.6. Physical Health: Females. Also shown in Table 2(b), the results of multiple logistic regression analysis for middle-aged females with diabetes indicated that after controlling for all other variables in the model, good physical health was not significantly related to routine checkup across states. However, those who reported having diabetes plus two or more other chronic conditions were about 3-9 times less likely to report good physical health compared to those who reported having diabetes only in the majority of the states.

\section{Discussion}

The purpose of this study was to determine whether physical and mental health status differ by routine checkup in middle-aged males and females with diabetes. For this target population, both good mental and physical health did not significantly differ related to having routine checkups across states. These results differ from prior research which showed that preventative care is related to both improved depressive symptoms and the perception of good overall health $[4,5,11]$. The differences in findings may be due to differing target populations. While our results focus on patients with diabetes, previous research focused on the general population as a whole. Therefore, it is possible that prevention efforts were in place as most of the patients were already under medical care. Thus, to our knowledge, our study is the first to focus only on middle-aged patients with diabetes as related to regular checkups.

However, the results of this study did show that for middle-aged males and females with diabetes, good physical and mental health were inversely related to having diabetes plus two or more other health conditions. This is generally consistent with prior research that showed chronic illnesses to be related to lower overall health in the general population [12]. As prior research focused primarily on the general population, our study focuses solely on middle-aged people with diabetes. For this target population, the comanagement and treatment of multiple chronic conditions may have a significant impact on their mental and physical health, and the assessment of comorbid conditions should be a focus for their care.

4.1. Limitations. The use of BRFFS data provided large, multiple samples to evaluate both physical and mental health (instead of "general" health) and separately for males and females (instead of together), which allowed us to determine whether patterns in variable relations were similar for different facets of health and by gender. In addition, BRFSS also provided current information, given that our dependent variables (mental and physical health) were measured within the last 30 days. However, BRFSS did not include variables that provided information about (1) current treatment and management of any mental or physical health condition, (2) current treatment and management of diabetes specifically, or (3) current management and severity of the chronic illnesses in addition to diabetes, all of which could have an impact upon mental and physical health. Future studies should include information about the current management and treatment of any mental and physical health conditions and should consider the influence of specific disease management and medication use in relation to its impact on mental and physical health in diabetics.

\section{Conclusions}

Because this study used population-based data, the results may generalize to males and females aged 45-64 with diabetes. Regarding the optimization of patient's mental and physical health, we recommend automatic mental and physical health screening for adults aged 45-64 with diabetes as well as screening for other chronic health conditions. General practitioners should assess comorbid conditions and treatments, refer to specialists as needed, and educate patients on the importance of proper management of diabetes in combination with any other chronic illnesses for maintaining good mental and physical health.

\section{Data Availability}

BRFSS 2017 data is available online from the CDC at https://www.cdc.gov/brfss/annual_data/annual_2017.html.

\section{Conflicts of Interest}

The authors declare that they have no conflicts of interest.

\section{References}

[1] Center for Disease Control and Prevention (CDC), "BRFSS prevalence and trends data," 2017a, https://www.cdc.gov/brfss/ brfssprevalence/index.html.

[2] Centers for Disease Control and Prevention (CDC), "National diabetes statistics report," 2017b, https://www.cdc.gov/diabetes/ data/statistics/statistics-report.html.

[3] Center for Disease Control and Prevention (CDC), "Behavioral risk factor surveillance system," 2018, https://www.cdc.gov/ brfss/index.html.

[4] D. Culica, J. Rohrer, M. Ward, P. Hilsenrath, and P. Pomrehn, "Medical checkups: who does not get them?" American Journal of Public Health, vol. 92, no. 1, pp. 88-91, 2002. 
[5] R. Dryden, B. Williams, C. McCowan, and M. Themessl-Huber, "What do we know about who does and does not attend general health checks? Findings from a narrative scoping review," $B M C$ Public Health, vol. 12, no. 723, pp. 1-23, 2012, http://www. biomedcentral.com/1471-2458/12/723.

[6] H. Eyre, R. Kahn, and R. M. Robertson, "Preventing cancer, cardiovascular disease, and diabetes: a common agenda for the American cancer society, the American diabetes association, and the American Heart Association," Diabetes Care, vol. 27, no. 7, pp. 1812-1824, 2004.

[7] I. Ganguli, J. Souza, and J. McWilliams, "Trends in use of the U.S. Medicare annual wellness visit, 2011-2014," Journal of American Medical Association, vol. 317, no. 21, pp. 2233-2235, 2017.

[8] A. Mehrota, A. M. Zaslavsky, and J. Z. Ayanian, "Preventative health examinations and preventative gynecological examinations in the United States," Archives of Internal Medicine, vol. 167, no. 17, pp. 1876-1883, 2007.

[9] A. Molarius, K. Berglund, C. Eriksson et al., "Socioeconomic conditions, lifestyle factors, and self-rated health among men and women in Sweden," European Journal of Public Health, vol. 17, no. 2, pp. 125-133, 2006.

[10] R. R. Rubin and M. Peyrot, "Quality of life and diabetes," Diabetes and Metabolism Research and Reviews, vol. 15, no. 3, pp. 205218, 1999, https://www.ncbi.nlm.nih.gov/pubmed/10441043.

[11] A. L. Siu, K. Bibbins-Domingo, D. C. Grossman et al., "Screening for depression in adults," JAMA, vol. 315, no. 4, pp. 380-387, 2016.

[12] T. W. Strine, D. P. Chapman, L. S. Balluz, D. G. Moriarty, and A. H. Mokdad, "The associations between life satisfaction and health-related quality of life, chronic illness, and health behaviors among U.S. community-dwelling adults," Journal of Community Health, vol. 33, no. 1, pp. 40-50, 2008.

[13] M. Tajvar, M. Arab, and A. Montazeri, "Determinants of healthrelated quality of life in elderly Tehran Iran," BMC Public Health, vol. 8, no. 323, 2008.

[14] P. E. Wandell, "Quality of life of patients with diabetes mellitus," Scandinavian Journal of Primary Health Care, vol. 23, no. 2, pp. 68-74, 2005. 